\title{
Persian translation and assessing the validity and reliability of the Questionnaire of Health Seeking Behavior of women living with HIV
}

\author{
Zahra Bayat Jozani ${ }^{1,2}$, Zohreh Mahmoodi $^{3}$, Mostafa Qorbani ${ }^{4}$, Minoo Mohraz ${ }^{2}$, Hoorvash Faraji Dana ${ }^{5}$ \\ ${ }^{1}$ Student Research Committee, Alborz University of Medical Sciences, Karaj, Iran \\ ${ }^{2}$ Iranian Research Center for HIV/AIDS, Iranian Institute for Reduction of High Risk Behaviors, Tehran University of Medical \\ Sciences, Tehran, Iran \\ ${ }^{3}$ Social Determinants of Health Research Center, Alborz University of Medical Sciences, Karaj, Iran \\ ${ }^{4}$ Non-Communicable Diseases Research Center, Alborz University of Medical Sciences, Karaj, Iran \\ ${ }^{5}$ Forensic Medicine Rajaie Hospital, Alborz University of Medical Sciences, Karaj, Iran
}

\begin{abstract}
Introduction: Health seeking behavior (HSB) is a highly important concept for assessment of health access and services. This study was performed to evaluate the validity and reliability of the Persian version of the Questionnaire of Health Seeking Behavior of women living with human immunodeficiency virus (HIV).

Material and methods: After obtaining permission from the questionnaire author we started our study in April 2018. We used the forward-backward method according to World Health Organization guidelines. In the first stage, qualitative assessment for assessing face and content validity was done by using 10 experts' and 10 HIV-positive women's ideas during panel and quantitative assessment was done using the content validity ratio (CVR) and content validity index (CVI). Reliability assessment was done among $80 \mathrm{HIV}$ women by Cronbach's $\alpha$. We conducted a pre-test among $10 \mathrm{HIV}$-positive women to discover any possible problems or issues.
\end{abstract}

Results: Internal reliability, and construct validity of the questionnaire were determined among expert and HIV-positive women participants. Overall internal reliability (Cronbach's $\alpha=0.81$ ) was high. SPSS 16 was used to analyze data, using analytical statistical methods including the $\chi^{2}$ test. After considering the quality of validity and the content of comments, the values of all the items, such as the CVI 0.93 and CVR 0.97, were obtained.

Conclusions: The results represented the validity and reliability of the Persian version of the questionnaire to estimate the HSB, and it is possible to use it as an assessment tool.

HIV AIDS Rev 2019; 18, 4: 279-284 DOI: https://doi.org/10.5114/hivar.2019.85915

Key words: health seeking behavior, human immunodeficiency virus (HIV), Persian.

\section{Introduction}

Acquired immunodeficiency syndrome (AIDS) is not only a disease with major medical issues, but also is a social phe- nomenon that can influence all human life aspects [1]. Suffering from human immunodeficiency virus (HIV) is not socially acceptable in most countries; most of the affected women are accused of immorality and prostitution [2].
Address for correspondence: Zohreh Mahmoodi, Social Determinants of Health Research Center, Alborz University of Medical Sciences, Karaj, Iran, phone: 989125474495 , e-mail: Zohrehmahmoodi2011@gmail.com
Article history:

Received: 11.09.2018

Received in revised form: 17.09.2018

Accepted: 18.09.2018

Available online: 15.03.2019
International Journal of HIV-Related Problem

HIV \& AIDS R e vi e w 
The fear of loss of reputation causes problems such as denial, secretiveness, depression, shyness, and covers up, the consequences of HIV detection, shame and suspicion of sex partners [3].

The concepts of health and disease relate to vital and cultural values. People from different cultures consider suffering as a threatening condition [4]. The social and cultural values train the individuals how to pay attention to one's health status, and how to evaluate one's health status, whether there are any threatening factors [4]. Searching and applying for health services may prove the responsibility and logical function of the sufferers. Moreover, these services would help one to expand one's opportunities to find an assured cure. The process of seeking health and care services starts with patient complaints. Some patients who were trapped in this process prefer seeing a doctor, some search for traditional treatments and the others grasp self-treatment without relying on doctors [5].

Health seeking behavior (HSB) begins immediately after signs and symptoms of the disease or after certain disease diagnostic processes. Selection of the type of service will greatly influence the early treatment, disease control, and recovery process. Ignoring the administration of specialized anti-virus treatments causes virus resistance and remarkable increase of virus load. This is specially considered in the transmission of the virus between mother and fetus. Free anti-virus medicines are available to sufferers in Iran; however, no functions to use and practice the questionnaire in the health-seeking behavior process are considered [6].

The most crucial steps towards health services are the process of data collection, processing of information and determination of treatment goals. Besides health care services, the effectiveness of treatment needs to be assessed thoroughly. The assessments will be used for documentation of the effectiveness of treatment, and they will represent many concepts on any potential scientific research $[7,8]$. Evaluation of satisfaction is a complex task that can be done by cognitive assessments of participants through the response they make to specific experiences [9].

In the results, it is suggested that we recruit the suitable tool in accordance with the subject and it is also important to note that the tool must be evaluated for reliability and justifiability. If a tool with later features is available, translation and matching the tool with the cultural situation is much more simplified and economical. However, it is vital to remember that in a translation-only approach without considering cultural accordance and without following valid instructions, the tool will probably lose its value [10,11].

The awareness of individuals estimates their status. Utilization of HSB is a crucial step to plan and execute the health interventions. One of the measuring tools of HSB is considering the patients based on individualized effective factors. In a previous study in Pakistan, a questionnaire was used to evaluate the conditions of a counseling center for the objective of HSB [12]. Due to the briefness of the later questionnaire, we represented the Persian version, in order to examine the stability and justifiability of the questionnaire.

\section{Material and methods}

\section{Design}

We conducted cross-sectional studies to assess the measurement properties of the Health Seeking Behavior. This research was approved by Alborz University of Medical Sciences by Abzums.Rec:1396.145 and Iranian Research Center for HIV/AIDS no: IR.TUMS.VCR. REC.1397.15 and Iranian Registry of Clinical Trials no: IRCT20160503027728N10.

\section{Participants and recruitment}

Our study participants were HIV-positive women 18 years old or above. All the participants were able to read and understand the questionnaire and according to the clinical observation and medical history none were diagnosed with mental illness. We recruited registered participants in a voluntary and counseling center of Imam Khomeini Hospital, Tehran, Iran.

\section{Data collection and tools}

The questionnaire was designed in English and Urdu [13]; for translation we used the forward-backward method according to World Health Organization guidelines [14]. After obtaining permission to use the survey instrument from the questionnaire author, the English questionnaire was forward translated by two bilingual HIV experts then the two versions and original version were discussed by an expert team. Back-translation was done into the initial Persian version by two other bilingual translators who were from the Iranian Research Center for Medical Sciences then we carried out discussion in a panel with both of them. Based on the experts' idea an initial Persian version was produced. The initial Persian version was back-translated into English by two HIV experts who were assistant professors of the Iranian Research Center for Medical Sciences. The research team compared the first and last version of the questionnaire and then a discussion meeting was held among the team of researchers and translators. Some change was made based on a final meeting. Then we sent the questionnaire by email to the questionnaire designer and it was approved and did not differ in terms of content. The final Persian version was tested for reliability and validity. Each phrase is scored by participants using a 5-point Likert scale (not important at all), and then, based on the following formula, each item is calculated for each statement, and if the score is equal to or greater than one and a half the phrase was appropriate for the subsequent analysis and was retained. Eventually, two separate parts were presented in the questionnaire: Part one with 20 and part two with 11 questions. The score of the questionnaire was in a Likert score.

For the purpose of psychometric evaluation of the questionnaire, formal and content validity was used both quantitatively and qualitatively. For face validity, 10 members 
of the target community (women living with HIV) who referred to the center were asked to assess the relevance of the item, obscurity, and misunderstandings, the difficulty of understanding the concepts and words, and whether they have a theoretical point of view, and write it down for us. In the next step, the quantitative effect of the item was used to reduce the number of phrases, to delete the inappropriate expressions and to determine the importance of each of the phrases.

Item Effect $=$ Frequency $(\%) \times$ Importance

The content of the questionnaire was also used in two qualitative and quantitative methods. In the qualitative study of the content, researchers from 10 experts of the fields were asked to check the quality of the questionnaire based on the criteria of grammar, the use of proper words, necessity, importance, the inclusion of proper phrases in their proper place and appropriate feedback. The content validity check was quantitatively used from 2 indicators, the content validity ratio (CVR) and the content validity index (CVI).

We chose this center because it is the first referral HIV center in Iran, which is located in Imam Khomeini Hospital, Infectious Diseases Department. All the services including laboratory tests, counseling and social services and medications are free of charge.

\section{Results}

Among 88 patients 80 participants completed questionnaires.

\section{General characteristics}

The mean age of the respondents to the questionnaires was calculated to be $35.73 \pm 6.34$ (43.32-37.15) years. Other demographic features are shown in Table 1.

\section{Validity}

\section{Face validity}

For face validity $10 \mathrm{HIV}$-positive women positive were participants for this section. Further modifications were made to the questionnaire. According to their opinion we made changes in the content of some items. However, as the impact score of any statement was not less than 1.5 , no statement was deleted.

\section{Content validity}

In qualitative content validation, some modifications were made based on the experts' opinions. However, after considering the quality of validity and the content of comments, the values of all the items, such as CVI 0.93, CVR 0.97 and SCVI (0.90), were obtained, none of the statements was deleted in this step, so 31 statements were qualified for the next step.
Table 1. Demographic characteristics of participants

\begin{tabular}{|c|c|c|c|}
\hline Status/Variable & $F$ & $\%$ & Mean \pm SD \\
\hline \multicolumn{4}{|l|}{ Age } \\
\hline $25-40$ & 52 & 64.9 & \multirow[t]{2}{*}{$35.73 \pm 6.34$} \\
\hline$>41$ & 28 & 35.1 & \\
\hline \multicolumn{4}{|l|}{ Education (years) } \\
\hline Illiterate & 5 & 6.2 & \multirow[t]{4}{*}{$8.91 \pm 4.46$} \\
\hline Primary or secondary school & 31 & 39.5 & \\
\hline High school & 36 & 44.9 & \\
\hline Bachelor degree & 7 & 8.8 & \\
\hline \multicolumn{4}{|l|}{ Job } \\
\hline Jobless & 1 & 1.2 & \multirow[t]{4}{*}{73.8} \\
\hline Home worker & 51 & 63.9 & \\
\hline Full-time job & 8 & 9.9 & \\
\hline Part-time job & 20 & 24.9 & \\
\hline \multicolumn{4}{|l|}{ Income (RIAL) } \\
\hline $0-6,000,000$ & 59 & 17.4 & \multirow{4}{*}{$\begin{array}{c}317.81 \pm \\
468.47\end{array}$} \\
\hline $601,000,000-10,000,000$ & 14 & 8.8 & \\
\hline $10,000,001-2,000,000$ & 7 & & \\
\hline$>2,000,000$ & 0 & 11.2 & \\
\hline \multicolumn{4}{|l|}{ Husband Income)RIAL) } \\
\hline $0-6,000,000$ & 9 & 54.1 & \multirow{4}{*}{$\begin{array}{c}1191139.24 \\
\pm 896693.33\end{array}$} \\
\hline $601,000,000-10,000,000$ & 43 & 27.2 & \\
\hline $10,000,001-2,000,000$ & 22 & 3.75 & \\
\hline$>2,000,000$ & 3 & 37.6 & \\
\hline \multicolumn{4}{|l|}{ Insurance } \\
\hline Without & 30 & 17.4 & \\
\hline Private & 14 & 45.2 & \\
\hline Governmental & 36 & 22.7 & \\
\hline \multicolumn{4}{|l|}{ Marital status } \\
\hline Single with partner & 18 & 15.2 & \\
\hline Spouse & 12 & 60.9 & \\
\hline Married & 49 & 15.5 & \\
\hline Widow/Divorced & 12 & 12.7 & \\
\hline \multicolumn{4}{|l|}{ Marital duration (years) } \\
\hline Less than 5 years & 10 & 32.4 & \\
\hline $5-10$ & 26 & 53.8 & \\
\hline$>10$ & 43 & 49.8 & \\
\hline \multicolumn{4}{|l|}{ Number of partners } \\
\hline 1 & 40 & 49.8 & \\
\hline $2-3$ & 35 & 32.4 & \\
\hline$>3$ & 5 & 53.8 & \\
\hline
\end{tabular}

\section{Reliability measures}

We calculated Cronbach's a for internal consistency of the questionnaire consisting of two main domains, health seeking behavior, and Healthcare Services. All domains showed acceptable internal consistency. Internal reliability of the questionnaire was determined among expert and HIV-positive women participants. Overall internal reliability (Cronbach's $\alpha$ $=0.81$ ) was high. Finally, all the questions were accepted. 
Table 2. Distribution of the quantitative content validity indexes of Health Seeking Behavior questionnaire

\begin{tabular}{|c|c|c|c|c|c|c|}
\hline \multirow{2}{*}{\multicolumn{2}{|c|}{ Question }} & \multirow{3}{*}{$\begin{array}{l}\text { CVR } \\
0.99 \\
\end{array}$} & \multicolumn{4}{|c|}{ CVI } \\
\hline & & & \multirow{2}{*}{\begin{tabular}{c|} 
Total \\
1
\end{tabular}} & \multirow{2}{*}{$\begin{array}{l}\mathrm{C} \\
1\end{array}$} & \multirow{2}{*}{$\frac{R}{0.8}$} & \multirow{2}{*}{$\begin{array}{c}\mathrm{S} \\
0.93\end{array}$} \\
\hline 1. & What was your reaction after observing the first HIV symptoms? & & & & & \\
\hline 2. & Where do you refer to receive HIV treatment? & 0.99 & 1 & 1 & 0.6 & 0.86 \\
\hline 3. & After the HIV positive test, where do you go for treatment except HIV treatments? & 1 & 1 & 1 & 1 & 1 \\
\hline 4. & Do you have enough information about HIV and HIV drugs? & 1 & 1 & 1 & 1 & 1 \\
\hline 5. & Do you take medicine continuously? & 0.99 & 1 & 1 & 1 & 1 \\
\hline 6. & Is the treatment accessible for you at a counseling center? & 0.85 & 1 & 1 & 1 & 1 \\
\hline 7. & Do you have any problems to take medicine? & 1 & 1 & 1 & 0.8 & 0.93 \\
\hline 8. & Which problem for taking medicine do you have? & 1 & 1 & 1 & 1 & 1 \\
\hline 9. & What else can you do except taking medicine? & 0.9 & 0.6 & 0.8 & 0.8 & 0.73 \\
\hline 10. & Did you have sex with your sexual partner during the past 6 months? & 1 & 1 & 1 & 1 & 1 \\
\hline 11. & If yes, did you use a condom? & 1 & 0.9 & 1 & 1 & 0.96 \\
\hline 12. & If no, what is your reason for not using a condom? & 1 & 1 & 1 & 1 & 1 \\
\hline 13. & Do you consider going anywhere else to treat yourself? & 1 & 0.9 & 0.9 & 1 & 0.93 \\
\hline 14. & What are the advantages of going to different centers to treat HIV/AIDS? & 0.9 & 0.4 & 0.9 & 0.9 & 0.73 \\
\hline 15. & What are the disadvantages of going to different centers to treat HIV/AIDS? & 0.9 & 0.8 & 0.9 & 0.9 & 0.86 \\
\hline 16. & Do you tell anybody that you go to this special center? & 1 & 1 & 1 & 1 & 1 \\
\hline 17. & Who knows you go to the voluntary and counseling center? & 1 & 1 & 1 & 1 & 1 \\
\hline 18. & What do you advise to anybody with the HIV diagnosis? & 0.9 & 0.6 & 0.9 & 0.7 & 0.73 \\
\hline 19. & What will happen to sufferers of HIV who don't take medicine? & 0.9 & 0.8 & 0.9 & 0.9 & 0.86 \\
\hline 20. & With whom do you think the affected individuals must have counseling? & 1 & 0.9 & 1 & 1 & 0.96 \\
\hline 21. & $\begin{array}{l}\text { How is the environment of the health center, where you got your treatment } \\
\text { at Imam Khomeini VCT? }\end{array}$ & 1 & 1 & 1 & 1 & 1 \\
\hline 22. & Is portable drinking water available? & 1 & 1 & 1 & 1 & 1 \\
\hline 23. & Is the sitting arrangement sufficient? & 1 & 1 & 1 & 1 & 1 \\
\hline 24. & Are any toilets available? & 1 & 1 & 1 & 1 & 1 \\
\hline 25. & How is the attitude of the health care providers of HIV center towards you? & 1 & 1 & 1 & 1 & 1 \\
\hline 26. & How is the attitude of the health care provider except the HIV center towards you? & 1 & 1 & 1 & 1 & 1 \\
\hline 27. & Have you faced any difficulties in talking to staff about your symptoms? & 1 & 1 & 1 & 1 & 1 \\
\hline 28. & Have you felt disgrace while getting treatment at the hospital? & 1 & 1 & 1 & 1 & 1 \\
\hline 29. & Does staff give sufficient time to respond to your queries? & 1 & 1 & 1 & 1 & 1 \\
\hline 30. & Who informed you about your next visit? & 1 & 1 & 1 & 1 & 1 \\
\hline 31. & Will you continue using treatment at Imam Khomeini voluntary and counseling center? & 1 & 1 & 1 & 1 & 1 \\
\hline
\end{tabular}

\section{Discussion}

The purpose of this study was to assess the reliability and validity of the Persian questionnaire tool for measuring health seeking behavior among HIV-positive women. The final Persian version of the health seeking behavior questionnaire for HIV/AIDS consists of 31 items and measures behavior in 2 subscale. It is necessary to use a reliable questionnaire including all the questions and dimensions to evaluate various aspects entirely.
According to a review article, the most common barriers for seeking care and HIV treatment are related to economic factors such as cost of treatment and transportation [15]. Stigma towards HIV in the community is strong and widespread, which may lead to less information seeking among HIV affected people, specially women [2]. The effect of age and sex on health seeking behavior is significant and is associated with health related behaviors. Optimal health is perceived as a priority, but this perception is not translated into preventative action [16]. 
This is probably symptomatic of different socio-cultural dynamics within the Iranian context. Sara MacKian's study was considered to find the important questions and the evaluated parts which consisted of the main influential factors on health seeking behavior, such as geographical factors like distance, the social influential factors, financial and economic factors, cultural and organizational factors that were represented in other researchers' study [17].

The instruments include different dimensions depending on the authors' theoretical concept of health seeking behavior. One such instrument, a health seeking behavior questionnaire for STI, includes socio-demographic characteristics (i.e., age, nationality, level of education, employment status), STI/HIV knowledge, HIV risk perceptions, sexual history, sex practices during the symptomatic period, partner patterns, condom use, perceived seriousness of symptoms, attitudes related to safer sex practices, self-treatment practices and health care-seeking behavior for symptoms [18].

According to the questionnaire, we asked the participants about their financial status to evaluate the impact of economic issues on the questionnaire. Finding the best and individualized service for each patient depends on many factors and the most noticeable ones are financial status, geographical distance to the counseling center and the individual's awareness and attitude. Some considered issues that can be supposed as organizational influential factors are the service quality, medicine, the condition and status of the service center and the service provider's behavior.

The individual's awareness and attitude towards HIV and sexual transmitted disease, the desired action of diagnosis and the early treatment determine the individual's attempt towards HSB. We must include questions about the individual's awareness of ways of transmission and non-transmission. According to individual comprehension of danger, we can recognize his condition and status of hygiene, future life of sufferers who do/do not take medicine, his thoughts and attitudes. Individuals' adherence to treatment depends on taking medicine, the problems of not taking medicine and regular access to medicine, so the related questions were necessary in this section.

Research on HSB of HIV is problematic, because of its asymptomatic nature. Clinical examinations, signs and symptoms are not present and specifically identical to many other diseases. In doing so, we must use the laboratory diagnosis to reach the definitive diagnosis [18].

The individuals' first action after the definitive diagnosis determines sufferers' path of HSB. It is vital to apply for a counselor, see a doctor and start the treatment as soon as possible. Therefore, we made the related questions. The support of family and friends and providing social support for sufferers is a principal factor to decrease the disease libel level and encourage them to be stable for treatment. Considering these items and helping them to be empowered and have disclosure about their disease, social hygienic services must be available for them. The patient's satisfaction and reliability of his treatment at counseling centers should be studied, because it might influence the process of counselors' services.

\section{Conclusions}

The current study proved that the Persian version of the HSB questionnaire considering women suffering from $\mathrm{HIV}$ is reliable and justifiable compared with the original version. This tool can be used in behavioral studies.

\section{Acknowledgments}

This original study was based on the thesis of the graduate faculty, Alborz University of Medical Sciences. We gratefully thank the Vice Chancellor of Alborz University of Medical Sciences and the Iranian Center for Medical Sciences for funding this study and scientific support of the Clinical Research Development Unit of Kamali Hospital. Lastly, we would like to thank all participants for their kind collaboration.

\section{Conflict of interest}

The authors declare no potential conflicts of interest with respect to the research, authorship, and/or publication of this article.

\section{References}

1. Moradi G, Malekafzali H, Naieni K, Rashidian A, Vazirian P, Mirzazadeh A, et al. HIV/AIDS situation in economic cooperation countries; achievement and gaps toward millennium development goals. JFRH 2011; 5: 1-9.

2. Jackson-Best F, Edwards N. Stigma and intersectionality: a systematic review of systematic reviews across HIV/AIDS, mental illness, and physical disability. BMC Public Health 2018; 18: 919.

3. Hutchinson P, Dhairyawan R. Shame and HIV: strategies for addressing the negative impact shame has on public health and diagnosis and treatment of HIV. Bioethics 2018; 32: 68-76.

4. Mullens AB, Kelly J, Debattista J, Phillips TM, Gu Z, Siggins F. Exploring HIV risks, testing and prevention among sub-Saharan African community members in Australia. Int J Equity Health 2018; 17: 62.

5. Kroeger A. Anthropological and socio-medical health care research in developing countries. Soc Sci Med 1983; 17: 147-161.

6. Draft Protocol. A rapid assessment of health seeking behavior in relation to sexually transmitted disease. 1995. Available at: http://www. Who.int/hiv/topics/en/healthcareseeking.pdf (Accessed: 14.11.2016).

7. Occupational Therapy Practice Framework: Domain and Process. $3^{\text {rd }}$ ed. Am J Occup Ther 2014; 68 (Suppl 1): S1-S48.

8. Schell BA, Scaffa M, Cohn ES. Willard and Spackman's occupational therapy. Lippincott Williams \& Wilkins, Philadelphia 2013.

9. Pakari N, Zahrani ST, Nasiri M, Mahmoodi Z. Persian translation and psychometric testing of the scales for measuring maternal satisfaction in normal and caesarean birth. Biosciences Biotechnology Research Asia 2016; 13: 339-346.

10. Carter LJ, Domholdt E. Rehabilitation research: principles and applications: Elsevier Health Sciences, 2013.

11. Borsa JC, Damásio BF, Bandeira DR. Cross-cultural adaptation and validation of psychological instruments: some considerations. Paideia (Ribeiro Preto) 2012; 22: 423-432. 
12. Van Widenfelt BM, Treffers PD, De Beurs E, Siebelink BM, Koudijs E. Translation and cross-cultural adaptation of assessment instruments used in psychological research with children and families. Clin Child Fam Psychol Rev 2005; 8: 135-147.

13. Bhutto AQ, Nisar N. Health-seeking behavior of people living with HIV/AIDS and their satisfaction with health services provided at a tertiary care hospital, Karachi, Pakistan. Eastern Mediterr Health J 2017; 23: 13-19.

14. WHO. Process of translation and adaptation of instruments. Available at:http://www.who.int/substance_abuse/research_tools/translation/en (Accessed: 05.04.2018).

15. Akullian AN, Mukose A, Levine GA, Babigumira JB. People living with HIV travel farther to access healthcare: a population-based geographic analysis from rural Uganda. J Int AIDS Soc 2016; 19: 20171.

16. Deeks A, Lombard C, Michelmore J, Teede H. The effects of gender and age on health related behaviors. BMC Public Health 2009; 9: 213.

17. Mackian S, Bedri N, Lovel H. Up the garden path and over the edge: where might health-seeking behaviour take us? Health Policy Plan 2004; 19: 137-146.

18. Jayabaskart T. Health care seeking behaviour of patients attending an STI clinic in Singapore. National University of Singapore, 2004. 